\title{
Moderate and severe postendoscopic retrograde cholangiopancreatography pancreatitis despite prophylactic pancreatic stent placement: The effect of early prophylactic pancreatic stent dislodgement
}

\author{
Dana C Moffatt MD ${ }^{1,2}$, Pradermchai Kongkam MD ${ }^{1}$, Haritha Avula MD¹, \\ Stuart Sherman $M D^{1}$, Evan L Fogel MD ${ }^{1}$, Glen A Lehman MD ${ }^{1}$
}

DC Moffatt, P Kongkam, H Avula, S Sherman, EL Fogel, GA Lehman. Moderate and severe postendoscopic retrograde cholangiopancreatography pancreatitis despite prophylactic pancreatic stent placement: The effect of early prophylactic pancreatic stent dislodgement. Can J Gastroenterol 2011;25(4):215-219.

BACKGROUND: Placement of prophylactic pancreatic stents (PPS) is a method proven to reduce the rate and severity of postendoscopic retrograde cholangiopancreatography (ERCP) pancreatitis (PEP) in high-risk patients; however, PPS do not eliminate the risk completely. Early PPS dislodgement may occur prematurely and contribute to more frequent or severe PEP.

OBJECTIVE: To determine the effect of early dislodgement of PPS in patients with moderate or severe PEP.

METHOD: A total of 27,176 ERCP procedures from January 1994 to September 2007 for PPS placement in high-risk patients were analyzed. Patient and procedure data were analyzed to assess risk factors for PEP, and to evaluate the severity of pancreatitis, length of hospitalization and subsequent complications. Timing of stent dislodgment was assessed radiographically.

RESULTS: PPS were placed in 7661 patients. Of these, 580 patients (7.5\%) developed PEP, which was graded as mild in 460 (6.0\%), moderate in $87(1.1 \%)$ and severe in $33(0.4 \%)$. Risk factors for developing PEP were not different in patients who developed moderate PEP compared with those with severe PEP. PPS dislodged before $72 \mathrm{~h}$ in seven of $59(11.9 \%)$ patients with moderate PEP and five of 27 (18.5\%) patients with severe PEP $(P=0.505)$. The mean $( \pm S D)$ length of hospitalization in patients with moderate $\mathrm{PEP}$ with stent dislodgement before and after $72 \mathrm{~h}$ were $7.43 \pm 1.46$ days and $8.37 \pm 1.16$ days, respectively $(P=0.20)$. The mean length of hospitalization in patients with severe PEP whose stent dislodged before and after $72 \mathrm{~h}$ were $21.6 \pm 6.11$ and $22.23 \pm 3.13$ days, respectively $(\mathrm{P}=0.96)$.

CONCLUSION: Early PPS dislodgement was associated with moderate and severe PEP in less than 20\% of cases and was not associated with a more severe course. Factors other than ductal obstruction contribute to PEP in high-risk patients undergoing ERCP and PPS placement.

Key Words: Complications; ERCP; Pancreatic stent; Post-ERCP pancreatitis

Dlacement of prophylactic pancreatic stents (PPS) has become a 1 standard treatment to reduce the rate of postendoscopic retrograde cholangiopancreatography (ERCP) pancreatitis (PEP) in high-risk patients undergoing ERCP. A recent randomized controlled trial from Japan (1) demonstrated an effective reduction in the rate of PEP from $13.6 \%$ to $3.2 \%$ using PPS in a consecutive cohort of patients at high risk for PEP. A meta-analysis (2) demonstrated a decline in the rate of PEP from $15.5 \%$ (43 of 275 ) to $5.8 \%$ (12 of 206) with PPS. This metaanalysis also reported severe PEP in seven of 275 patients who did not
Une pancréatite modérée à grave après

cholangiopancréatographie rétrograde endoscopique malgré l'installation d'une endoprothèse pancréatique prophylactique : l'effet du délogement rapide de l'endoprothèse pancréatique prophylactique

HISTORIQUE : L'installation d'endoprothèses pancréatiques prophylactiques (EPP) est une méthode démontrée pour réduire le taux et la gravité de la pancréatite après cholangiopancréatographie rétrograde postendoscopique (CPRE; pancréatite après CPRE : $\mathrm{PPE}$ ) chez les patients à haut risque. Cependant, l'EPP n'élimine pas complètement ce risque. Un délogement de l'EPP peut se produire prématurément et contribuer à des occurrences de PPE plus fréquentes ou plus graves.

OBJECTIF : Déterminer l'effet du délogement rapide de l'EPP chez les patients ayant une PPE modérée à grave.

MÉTHODOLOGIE : Au total, les chercheurs ont analysé 27176 CPRE exécutées entre janvier 1994 et septembre 2007 en vue d'installer une EPP chez des patients à haut risque. Ils ont analysé les patients et les données de l'intervention pour évaluer les facteurs de risque de PPE ainsi que la gravité de la pancréatite, la durée d'hospitalisation et les complications subséquentes. Ils ont évalué le moment du délogement de l'endoprothèse par radiographie.

RÉSULTATS : Une EPP a été installée chez 7661 patients. De ce nombre, 580 patients $(7,5 \%)$ ont acquis une PPE, évaluée comme bénigne chez 460 d'entre eux $(6,0 \%)$, modérée chez 87 autres $(1,1 \%)$ et grave chez les 33 derniers $(0,4 \%)$. Les facteurs de risque de PPE ne différaient pas chez les patients qui acquéraient une PPE modérée par rapport à ceux qui présentaient une PPE grave. L'EPP s'est délogée avant 72 heures chez sept des 59 patients $(11,9 \%)$ ayant une PPE modérée et chez cinq des 27 patients $(18,5 \%)$ ayant une PPE grave $(\mathrm{P}=0,505)$. La durée d'hospitalisation moyenne $( \pm$ ÉT) chez les patients ayant une PPE modérée dont l'endoprothèse s'était délogée avant et après 72 heures était de 7,43 $\pm 1,46$ jours et de $8,37 \pm 1,16$ jours, respectivement $(\mathrm{P}=0,20)$. La durée d'hospitalisation moyenne chez les patients ayant une PPE grave dont l'endoprothèse s'était délogée avant et après 72 heures était de $21,6 \pm 6,11$ jours et de $22,23 \pm 3,13$ jours, respectivement $(P=0,96)$.

CONCLUSION : Le délogement rapide de l'EPP s'associait à une PPE modérée ou grave dans moins de $20 \%$ des cas et ne s'associait pas à une évolution plus grave. D'autres facteurs que l'obstruction ductale contribuent à la PPE chez les patients à haut risque qui subissent une CPRE et l'installation d'une EPP.

undergo PPS placement. The vulnerable period for PEP is unknown and, thus, the duration of prophylactic pancreatic stenting has not been quantified. Early outward migration and passage of PPS could theoretically lead to a higher incidence of PEP and a more severe course. The present article describes our experience with PPS in patients with moderate and severe PEP. We hypothesized that stent passage by $72 \mathrm{~h}$ after placement may occur prematurely and contribute to more frequent or severe PEP. The present study was performed to determine the rate of early passage of PPS in patients with moderate or severe PEP.

${ }^{1}$ Indiana University Medical Center, Indiana University, Indianapolis, Indiana, USA; ${ }^{2}$ University of Manitoba, Winnipeg, Manitoba

Correspondence: Dr Dana C Moffatt, St Boniface Hospital, C5011-409, Tache Avenue, Winnipeg, Manitoba R2H 2A6. Telephone 204-235-3282,

fax 204-233-7154, e-mail danamoffatt@shaw.ca

Received for publication February 19, 2010. Accepted October 10, 2010 




Figure 1) Diagram illustrating the flow of procedures and eligible patients throughout the study period. PPS Prophylactic pancreatic stents

\section{METHODS}

Patients

All patients who underwent ERCP with pancreatic stent placement over a 13-year period (January 1994 to September 2007) were identified from a prospectively collected ERCP database that has received research ethics board approval since 1994. Before being entered into the database, all patients provide informed consent for their treatment and follow-up data to be assessed for research purposes. Patients in the database were contacted via telephone within two weeks after their ERCP for follow-up and documentation of any major complications such as hospitalization, major bleeding, perforation or death. More detailed data were extracted from the hospital information system for patients that were admitted to University Hospital, Indiana, USA, with complications from ERCP.

\section{Procedure and complication definitions}

Stents were considered to be 'prophylactic' if they were $3 \mathrm{Fr}, 4 \mathrm{Fr}$ or $5 \mathrm{Fr}$ in diameter with no internal flange. Patients with the following characteristics were included: no pancreatic ductal disease, sphincter of Oddi dysfunction was confirmed or suspected, or a stent was placed for precut sphincterotomy. Patients with PPS' with an intraductal flange or known therapeutic pancreatic stents were excluded because they were not necessarily PPS. Patients meeting eligibility criteria for PPS who subsequently developed moderate or severe PEP and were hospitalized at University Hospital, were reviewed using standardized criteria to diagnose PEP and grade its severity (3). Mild PEP was defined as elevated amylase levels at least three times the upper limit of normal at more than $24 \mathrm{~h}$ after the procedure, requiring admission or prolongation of planned admission by two to three days. Moderate PEP was considered to be present in patients who required hospital admission for four to 10 days. Severe PEP was defined as pancreatitis requiring hospitalization for more than 10 days or any intensive care unit admission, development of necrosis or pseudocyst, or need for intervention (percutaneous or surgical).

All baseline patient characteristics including age and sex, and procedural information including sphincter of Oddi manometry, pancreatic sphincter of Oddi dysfunction, balloon dilation, dual sphincterotomy, pancreatography including tail filling, absence of chronic pancreatitis and normal cholangiogram were collected. Endoscopic
TABLE 1

Comparison of risk factors for postendoscopic retrograde cholangiopancreatography pancreatitis (PEP) between patients with moderate or severe PEP

\begin{tabular}{|c|c|c|c|}
\hline \multirow[b]{2}{*}{ Risk factor } & \multicolumn{2}{|c|}{ PEP } & \multirow[b]{2}{*}{$\mathbf{P}$} \\
\hline & Moderate $(n=59)$ & Severe $(n=27)$ & \\
\hline Sex, female & $47(79.7)$ & $25(92.6)$ & $0.209 *$ \\
\hline $\begin{array}{l}\text { Sphincter of Oddi manometry } \\
\text { performed }\end{array}$ & $56(94.9)$ & $24(88.9)$ & $0.373^{*}$ \\
\hline $\begin{array}{l}\text { Pancreatic sphincter of Oddi } \\
\text { dysfunction }\end{array}$ & $35(59.3)$ & $16(59.3)$ & $0.892^{\dagger}$ \\
\hline Balloon dilation & $5(8.5)$ & $4(14.8)$ & $0.453^{*}$ \\
\hline No sphincterotomy & $3(5.1)$ & $3(11.1)$ & $0.439^{\dagger}$ \\
\hline One sphincterotomy & $16(27.1)$ & $9(33.3)$ & \\
\hline Dual sphincterotomy & $40(67.8)$ & $15(55.6)$ & \\
\hline $\begin{array}{l}\text { Pancreatography including } \\
\text { filling of the tail }\end{array}$ & $47 / 58(81)$ & $24 / 27(88.9)$ & $0.533^{*}$ \\
\hline No chronic pancreatitis ${ }^{\Uparrow}$ & $42 / 58(72.4)$ & $24 / 27(88.9)$ & $0.156^{\ddagger}$ \\
\hline Normal cholangiogram** & 43/55 (78.2) & $21 / 26(80.8)$ & $1.000^{\ddagger}$ \\
\hline Risk factors, n (mean) & 6.29 & 6.56 & $0.380^{\S}$ \\
\hline
\end{tabular}

Data presented as $n$ (\%) or $n / n$ (\%) unless otherwise indicated. *Fisher's exact test; ${ }^{\dagger} \chi^{2}$ test; ${ }^{\ddagger}$ Continuity correction; ${ }^{\prime}$ t test; ${ }^{\top}$ One patient with moderate pancreatitis was excluded from the denominator because no pancreatogram or report describing the pancreatogram was available for review; however, the pancreatogram performed before this endoscopic retrograde cholangiopancreatography was normal; ${ }^{\star *}$ Three patients with moderate and one patient with severe pancreatitis were excluded from the denominator because a cholangiogram was not performed

procedures, medical records and imaging studies including plain abdomen $\mathrm{x}$-ray, endoscopic ultrasound, or computed tomography scan that had been performed during the hospitalization or follow-up period were reviewed to investigate the persistence of PPS in situ. The first and most recent dates that a PPS was identified on imaging or endoscopy, as well as the date it was initially placed were recorded and analyzed. Less than $72 \mathrm{~h}$ duration was used as the cut-off point to define early PPS passage. The primary outcome measurement was considered to be the duration of PPS in situ in moderate and severe PEP.

\section{Statistics}

For univariate analysis, the $t$ test or Wilcoxon rank sum test was used to assess continuous variables, while the $\chi^{2}$ test was used to calculate differences in categorical demographics and incidences. Calculation of ORs and $95 \%$ CIs served to assess the effect of early stent passage between groups of patients. A two-tailed $t$ test with $\mathrm{P}<0.05$ was considered to be statistically significant. SPSS version 16.0 (IBM Corporation, USA) was used to calculate all statistical values.

\section{RESULTS}

A total of 27,176 ERCP procedures over a 13-year period (January 1994 to September 2007) were analyzed. Pancreatic stents were placed in 10,014 procedures overall $(36.8 \%)$. Pancreatic stents were prophylactic in nature in 7661 procedures $(76.5 \%)$ and, of these, 580 patients (7.5\%) developed PEP. PEP was graded as mild in 460 (6.0\%) patients, moderate in $87(1.1 \%)$ and severe in $33(0.4 \%)$. Patients who were hospitalized at University Hospital for moderate $(n=59)$ or severe PEP $(n=27)$ were reviewed (Figure 1$)$.

Stent diameters in patients with moderate PEP were 3 Fr in $42.4 \%$, $4 \mathrm{Fr}$ in $35.6 \%$ and greater than $4 \mathrm{Fr}$ in $22.0 \%$. In patients with severe PEP, stent diameters were $3 \mathrm{Fr}$ in $51.9 \%, 4 \mathrm{Fr}$ in $25.9 \%$ and greater than $4 \mathrm{Fr}$ in $22.2 \%$. The frequency of risk factors for developing PEP was not significantly different between groups with severe versus moderate PEP (Table 1). Of eight risk factors for PEP, patients with moderate or severe PEP had a mean of 6.29 and 6.56 risk factors, respectively 
$(\mathrm{P}=0.380)$ (Table 1). Patients with moderate PEP whose stent passed before and after $72 \mathrm{~h}$ had a mean $( \pm \mathrm{SD})$ of $6.1 \pm 0.9$ and $6.3 \pm 1.3$ risk factors, respectively $(\mathrm{P}=0.6)$. Patients with severe PEP whose stent passed before and after $72 \mathrm{~h}$ had $6.4 \pm 1.5$ and $6.6 \pm 1.5$ risk factors, respectively $(\mathrm{P}=0.8)$.

PPS dislodged before $72 \mathrm{~h}$ in seven patients with moderate PEP $(11.9 \%)$ and in five patients with severe PEP (18.5\%) $(\mathrm{P}=0.505)$ (Figures 2A and B, respectively). The odds of developing moderate versus severe pancreatitis in patients who passed their PPS before three days was statistically nonsignificant (OR 0.59 [95\% CI 0.16 to 2.10]). The length of hospitalization in patients with moderate PEP whose stent passed before and after $72 \mathrm{~h}$ were $7.43 \pm 1.46$ days and $8.37 \pm 1.16$ days, respectively $(\mathrm{P}=0.20)$. The length of hospitalization in patients with severe PEP whose stent passed before and after $72 \mathrm{~h}$ were $21.60 \pm 6.11$ days and $22.23 \pm 3.13$ days, respectively $(\mathrm{P}=0.96)$.

A confounding variable was the coexistence of perforation in two moderate (periampullary perforation and pancreatic ductal perforation) and three severe (perforated duodenum) cases of PEP. None of the patients with perforation experienced early PPS dislodgement. When these patients were excluded from analysis, the length of hospitalization was $7.8 \pm 7.3$ days and $19.8 \pm 11.3$ days for moderate and severe PEP, respectively.

\section{DISCUSSION}

Moderate or severe PEP occurs less frequently than mild PEP in both low- and high-risk groups of patients undergoing ERCP. The rates of moderate and severe PEP reported in full-length articles with available data $(1,4-11)$ showed a mean of $4.68 \%$ and $2.41 \%$, respectively, in highrisk groups without PPS placement (Table 2). PPS have been shown to effectively reduce the rate of PEP - including moderate and severe PEP to $3.21 \%$ and $0.13 \%$, respectively. A review of five published randomized controlled trials (RCTs $[1,4,5,9,10]$ ) revealed rates of moderate and severe PEP of $1.33 \%$ (three of 226) and $0 \%$ ( 0 of 226), respectively. Previous studies comparing the rate of PEP between patients with and without stents were powered to detect differences in overall PEP rate, but were not powered to detect differences in less frequent moderate or severe PEP. All existing controlled studies reported fewer than 400 patients in the stented arm but, unfortunately, to detect statistically significant differences in the incidence of rare events, such severe PEP, sample sizes would need to be much larger for the study to be adequately powered. We have been using PPS regularly for the prevention of PEP since 1994, and more than 7000 ERCP procedures involving PPS placement were included in the present study. Overall, we observed an incidence of severe PEP of $0.4 \%$ in patients with PPS.

Placement of PPS in high-risk patients has resulted in a clinically and statistically important decline in PEP rates (including moderate

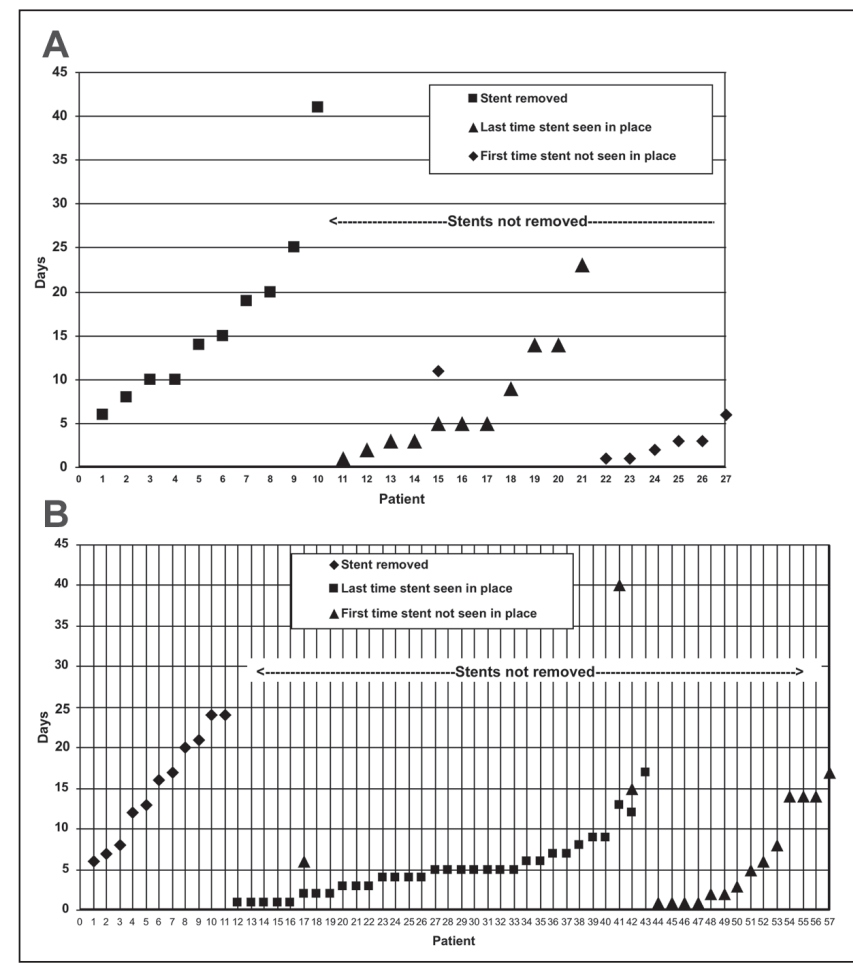

Figure 2) A Exact date of persistence or absence of prophylactic pancreatic stents (PPS) in high-risk patients who developed moderate pancreatitis. PPS were proven to have passed from the pancreatic duct by the third day in seven patients with severe postendoscopic retrograde cholangiopancreatography pancreatitis (PEP) (11.9\%). B Exact date of persistence or absence of PPS in high-risk patients who developed moderate PEP. PPS were proven to have passed from the pancreatic duct by the third day in five patients with moderate PEP (18.5\%)

and severe cases). However, results of the present study remind endoscopists that although the incidence of patients with severe PEP has markedly declined with PPS use, such pancreatitis still occurs. Informed consent for ERCP should still include severe pancreatitis as a possible complication. Our database uses standard PEP criteria and should be amenable to comparisons with other centres (12).

Within stented groups, it has been our general observation that moderate and severe PEP decreased during the past five years. Two

\section{TABLE 2}

Results compilation of nine published studies with available information for rates of moderate and severe pancreatitis in patients with and without protective pancreatic stents

\begin{tabular}{|c|c|c|c|c|c|c|c|c|c|c|c|c|c|}
\hline \multirow{3}{*}{$\begin{array}{l}\text { First author } \\
\text { (reference), year }\end{array}$} & \multirow[b]{3}{*}{ Study design } & \multirow[b]{3}{*}{ Indication } & \multirow{2}{*}{\multicolumn{3}{|c|}{$\mathbf{n}$}} & \multicolumn{8}{|c|}{ Pancreatitis } \\
\hline & & & & & & \multicolumn{2}{|c|}{ Acute } & \multicolumn{2}{|c|}{ Severe } & \multicolumn{2}{|c|}{ Moderate } & \multicolumn{2}{|c|}{ Mild } \\
\hline & & & Total & NS & Stent & NS & Stent & NS & Stent & NS & Stent & NS & Stent \\
\hline Smithline (4), 1993 & $\mathrm{RCT}$ & BES for SOD, precut & 93 & 50 & 43 & 9 & 6 & 2 & 0 & 2 & 1 & 5 & 5 \\
\hline Tarnasky (5), 1998 & $\mathrm{RCT}$ & BES SOD & 80 & 39 & 41 & 10 & 1 & 0 & 0 & 5 & 1 & 5 & 0 \\
\hline Aizawa (6), 2001 & Case-control & Biliary balloon dilation & 130 & 92 & 38 & 6 & 0 & 0 & 0 & 0 & 0 & 6 & 0 \\
\hline Fogel (7), 2002 & Case-control & SOD & 692 & 440 & 252 & 85 & 34 & 13 & 1 & 21 & 9 & 51 & 24 \\
\hline Norton (8), 2002 & Case-control & Papillectomy & 28 & 18 & 10 & 2 & 2 & 0 & 0 & 0 & 0 & 2 & 2 \\
\hline Harewood (9), 2005 & $\mathrm{RCT}$ & Papillectomy & 19 & 9 & 10 & 3 & 0 & 0 & 0 & 0 & 0 & 3 & 0 \\
\hline Fazel (10), 2003 & $\mathrm{RCT}$ & $\begin{array}{l}\text { Difficult cannulation, BES, } \\
\text { SOD }\end{array}$ & 74 & 36 & 38 & 10 & 2 & 3 & 0 & 2 & 0 & 5 & 2 \\
\hline Freeman (11), 2004 & Case-control & High-risk ERCP procedures & 225 & 3 & 222 & 2 & 32 & 1 & 0 & 1 & 12 & 0 & 20 \\
\hline Sofuni (1), 2007 & $\mathrm{RCT}$ & High risk & 197 & 103 & 94 & 14 & 3 & 0 & 0 & 6 & 1 & 8 & 2 \\
\hline Total, n & & & 1538 & 790 & 748 & 141 & 80 & 19 & 1 & 37 & 24 & 85 & 55 \\
\hline$\%$ & & & & & & 17.85 & 10.70 & 2.41 & 0.13 & 4.68 & 3.21 & 10.76 & 7.35 \\
\hline
\end{tabular}

BES Biliary sphincterotomy; ERCP Endoscopic retrograde cholangiopancreatography; NS No stent; RCT Randomized controlled trial; SOD Sphincter of Oddi dysfunction 
RCTs conducted before $2002(4,5)$ reported rates of moderate and total PEP in stented patients at $2.3 \%$ and $14 \%$ (4), and $2.4 \%$ and $2.4 \%$ (5), respectively, whereas three RCTs conducted after 2002 $(1,9,10)$ reported the rates at $0 \%$ and $0 \%(9), 0 \%$ and $5.3 \%(10)$, and $1.1 \%$ and $3.2 \%(1)$, respectively. None of the five RCTs reported severe PEP. In our series, the rate of moderate PEP from 1994 to 2002, versus after 2002 to 2007 , was $1.8 \%$ (67 of 3650 ) versus $0.5 \%$ (20 of 4011) $(\mathrm{P}<0.001)$, respectively. Over these same time intervals, our rate of severe PEP was $0.5 \%$ (20 of 3650 ) versus $0.3 \%$ (13 of 4011), respectively $(\mathrm{P}=0.135)$. We speculate that this may be due to greater attention to cannulation technique and less frequent filling of the pancreatic ductal body and tail, especially in patients with a normal pancreatic body and tail seen on noninvasive imaging.

Only one study to date has evaluated how long PPS need to be in place to prevent PEP, and whether early passage contributes to the rate of PEP. Chahal et al (13) recently reported that by $24 \mathrm{~h}$, patients with 3 Fr and 5 Fr stents had stent dislodgement rates of $13 \%$ and $50 \%$, respectively. At seven days, stent dislodgement with $3 \mathrm{Fr}$ and $5 \mathrm{Fr}$ stents had occurred at a rate of $61 \%$ and $91 \%$, respectively. Stent fallout at $24 \mathrm{~h}$ was not a significant risk for PEP. However, another study from our group (14) demonstrated a significantly higher rate of PEP in patients whose PPS were immediately removed following needle-knife precut sphincterotomy compared with patients whose PPS were left for one week or longer (21\% versus 2\%, respectively).

Studies of post-ERCP serum enzyme levels showing statistically significant elevation $2 \mathrm{~h}$ to $4 \mathrm{~h}$ after the procedure correlate with clinical pancreatitis. Testoni et al (15) found that elevated amylase levels determined at $4 \mathrm{~h}$ and $8 \mathrm{~h}$ postprocedure yielded $68 \%$ sensitivity to predict PEP. Gottlieb et al (16) demonstrated that normal serum amylase and lipase levels $2 \mathrm{~h}$ post-ERCP had positive and negative predictive values of $97 \%$ and $0.9898 \%$, respectively. Thomas and Sengupta (17) suggested that $4 \mathrm{~h}$ serum amylase levels less than 1.5 times the upper limit of normal yielded a negative predictive value for PEP of $100 \%$. This suggests that PPS should be in place for at least a few hours after ERCP when initial pancreatitis is occurring. Based on previous studies $(18,19)$, the rate of spontaneous passage of unflanged stents varied from $65 \%$ to $95 \%$ depending on the type, diameter, length and time point of rechecking stent position. The majority of studies determine spontaneous stent passage rates at one or more weeks after ERCP. The frequency of passage of stents at one, two, or three days or more after ERCP has received limited evaluation. A recent study from Japan (1) demonstrated a spontaneous stent passage rate of $96 \%$ by three days with unflanged, straight, $5 \mathrm{Fr}, 3 \mathrm{~cm}$ PPS. The observed PEP rate was $3.2 \%$ without any severe PEP. In contrast, our study revealed that $80 \%$ of reviewed patients still had PPS in situ longer than three days. We suspect this difference was due to the longer length stents used in our groups $(6.4 \pm 2.8 \mathrm{~cm}$ and $5.4 \pm 2.5 \mathrm{~cm}$ in moderate and severe PEP, respectively). Additionally, the present study demonstrated that in patients with moderate and severe PEP, more than $80 \%$ of PPS remained in place. Early PPS passage does not appear to contribute to the frequency and severity of PEP. A more recent study by Chahal et al (13) evaluated the spontaneous dislodgement rates of $5 \mathrm{Fr}$ versus $3 \mathrm{Fr}$ stents and, comparable with our data, found a statistically similar rate of PEP between the groups ( $9 \%$ versus $14 \%$, respectively $[\mathrm{P}=0.3]$ ).

\section{REFERENCES}

1. Sofuni A, Maguchi H, Itoi T, et al. Prophylaxis of post-endoscopic retrograde cholangiopancreatography pancreatitis by an endoscopic pancreatic spontaneous dislodgement stent. Clin Gastroenterol Hepatol 2007;5:1339-46.

2. Singh P, Das A, Isenberg G, et al. Does prophylactic pancreatic stent placement reduce the risk of post-ERCP acute pancreatitis? A meta-analysis of controlled trials. Gastrointest Endosc 2004:60:544-50.

3. Cotton PB, Lehman G, Vennes J, et al. Endoscopic sphincterotomy complications and their management: An attempt at consensus. Gastrointest Endosc 1991;37:383-93.
This study, however, did not specifically comment on the time to dislodgement in cases of PEP.

Our study was limited in the following ways: First, our ability to obtain detailed information on disease course in PEP was limited to patients who were hospitalized at our institution. Although our follow-up for patients with PEP was incomplete, all patients at our facility are instructed to stay within $30 \mathrm{~min}$ of our institution for $24 \mathrm{~h}$ post-ERCP. Also, follow-up telephone calls are made by our staff to gather data on post-ERCP complications one to two weeks after the procedure. Furthermore, given that our hospital is the main tertiary referral centre for pancreatic diseases in Indiana (USA) and the surrounding areas, this may have biased our study by selecting more patients with complicated pancreatic and biliary disease, more severe disease course and more severe complications. However, we believe that this does not invalidate our conclusions because it may have biased the results in either direction. Second, the study was retrospective in nature and no defined protocol for abdominal imaging was in place during its course; therefore, incomplete data were available for assessing the exact date of pancreatic stent dislodgement. However, in all patients described in the present study, abdominal $\mathrm{x}$-rays, computed tomography scans and/or magnetic resonance imaging were available to identify the presence or absence of PEP within $24 \mathrm{~h}$ of admission.

\section{CONCLUSION}

It has been postulated that the pathogenesis of PEP involves several mechanisms including obstruction to outflow of pancreatic juice at the level of the papilla, chemical or allergic injury from injected dye, hydrostatic injury from pressure of injection, infection, mechanical trauma from guide wires and thermal injury from electrocautery (20). PPS address only one factor in the etiology of PEP by preventing the obstruction of outflow of pancreatic juice. It is possible, however, that PEP may have already been initiated before placement of PPS or, conversely, may be entirely unrelated to pancreatic ductal obstruction. Nevertheless, the reduction of PEP with placement of PPS strongly suggests that the one factor corrected by stents is important. Further studies are needed to address other factors responsible for PEP.

\section{MAIN POINTS}

1. PPS placement in high-risk individuals was associated with a moderate risk of PEP, and a very low risk of severe PEP.

2. Early dislodgement of PPS was not associated with an increased risk of PEP, nor a more severe course of PEP.

3. Factors other than main pancreatic duct obstruction contribute to the occurrence of PEP in high-risk patients.

CONFLICTS OF INTEREST: The authors declare no conflict of interest in relation to this article including employment, consultancies, stock ownership, honoraria, paid expert testimony, patent applications, and research and travel grants within three years of beginning the work presented. No financial support or compensation for this research was provided.
4. Smithline A, Silverman W, Rogers D, et al. Effect of prophylactic main pancreatic duct stenting on the incidence of biliary endoscopic sphincterotomy-induced pancreatitis in high-risk patients. Gastrointest Endosc 1993;39:652-7.

5. Tarnasky PR, Palesch YY, Cunningham JT, et al. Pancreatic stenting prevents pancreatitis after biliary sphincterotomy in patients with sphincter of Oddi dysfunction. Gastroenterology 1998;115:1518-24.

6. Aizawa T, Ueno N. Stent placement in the pancreatic duct prevents pancreatitis after endoscopic sphincter dilation for removal of bile duct stones. Gastrointest Endosc 2001;54:209-13. 
7. Fogel EL, Eversman D, Jamidar P, et al. Sphincter of Oddi dysfunction: Pancreaticobiliary sphincterotomy with pancreatic stent placement has a lower rate of pancreatitis than biliary sphincterotomy alone. Endoscopy 2002;34:280-5.

8. Norton ID, Gostout CJ, Baron TH, et al. Safety and outcome of endoscopic snare excision of the major duodenal papilla. Gastrointest Endosc 2002;56:239-43.

9. Harewood GC, Pochron NL, Gostout CJ. Prospective, randomized, controlled trial of prophylactic pancreatic stent placement for endoscopic snare excision of the duodenal ampulla. Gastrointest Endosc 2005;62:367-70.

10. Fazel A, Quadri A, Catalano MF, et al. Does a pancreatic duct stent prevent post-ERCP pancreatitis? A prospective randomized study. Gastrointest Endosc 2003;57:291-4.

11. Freeman ML, Overby C, Qi D. Pancreatic stent insertion: Consequences of failure and results of a modified technique to maximize success. Gastrointest Endosc 2004;59:8-14.

12. Lehman GA. Endoscopic sphincter of Oddi manometry: A clinical practice and research tool. Gastrointest Endosc 1991;37:490-2.

13. Chahal P, Tarnasky PR, Petersen BT, et al. Short $5 \mathrm{Fr}$ vs long $3 \mathrm{Fr}$ pancreatic stents in patients at risk for post-endoscopic retrograde cholangiopancreatography pancreatitis. Clin Gastroenterol Hepatol 2009; 7:834-9.
14. Sherman S, Earle D, Bucksot L, et al. Does leaving a main pancreatic duct stent in place reduce the incidence of precut biliary sphincterotomy (ES)-induced pancreatitis? A final analysis of a randomized prospective study. Gastrointestinal Endosc 1996;43:A413.

15. Testoni PA, Bagnolo F, Caporuscio S, et al. Serum amylase measured four hours after endoscopic sphincterotomy is a reliable predictor of postprocedure pancreatitis. Am J Gastroenterol 1999;94:1235-41.

16. Gottlieb K, Sherman S, Pezzi J, et al. Early recognition of postERCP pancreatitis by clinical assessment and serum pancreatic enzymes. Am J Gastroenterol 1996;91:1553-7.

17. Thomas PR, Sengupta S. Prediction of pancreatitis following endoscopic retrograde cholangiopancreatography by the 4-h post procedure amylase level. J Gastroenterol Hepatol 2001;16:923-6.

18. Rashdan A, Fogel EL, McHenry L Jr, et al. Improved stent characteristics for prophylaxis of post-ERCP pancreatitis. Clin Gastroenterol Hepatol 2004;2:322-9.

19. Lawrence C, Cotton PB, Romagnuolo J, et al. Small prophylactic pancreatic duct stents: An assessment of spontaneous passage and stent-induced ductal abnormalities. Endoscopy 2007;39:1082-5.

20. Sherman S, Lehman GA. ERCP- and endoscopic sphincterotomyinduced pancreatitis. Pancreas 1991;6:350-67. 


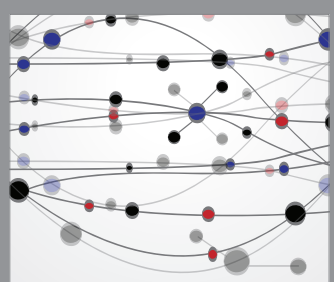

The Scientific World Journal
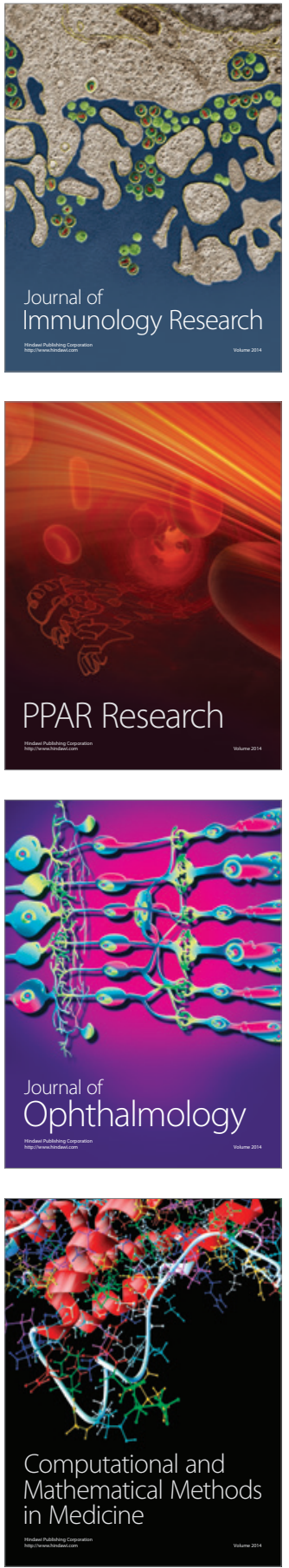

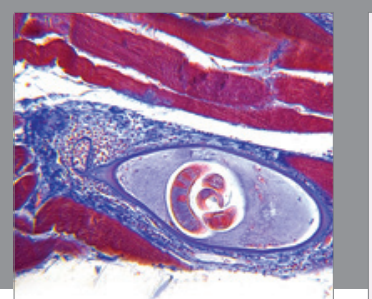

Gastroenterology Research and Practice

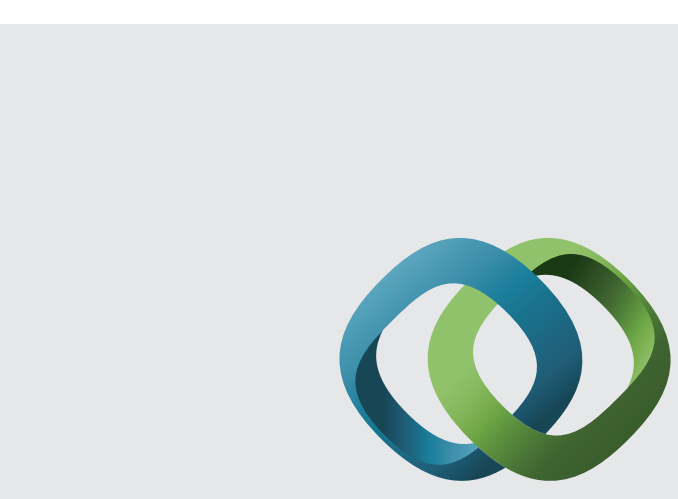

\section{Hindawi}

Submit your manuscripts at

http://www.hindawi.com

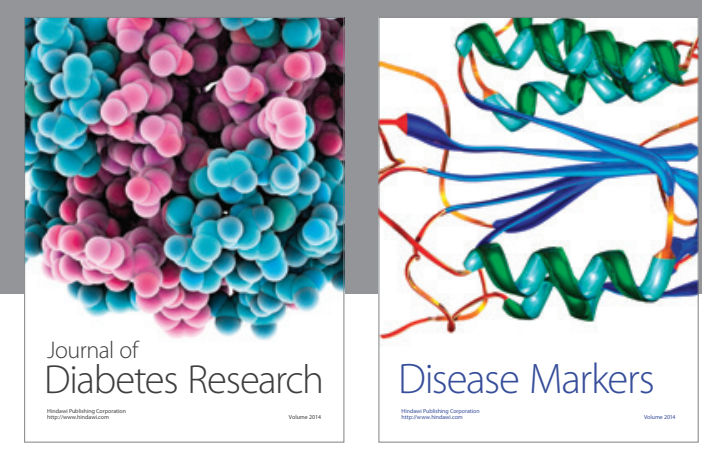

Disease Markers
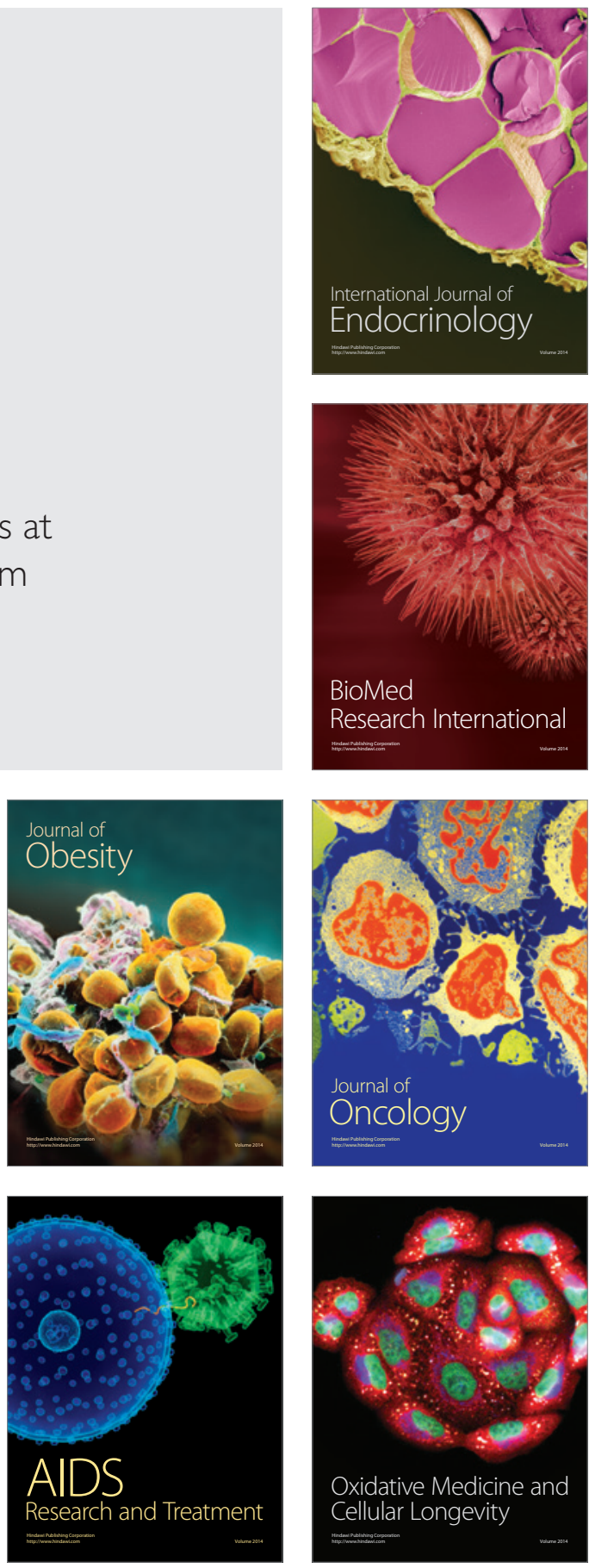